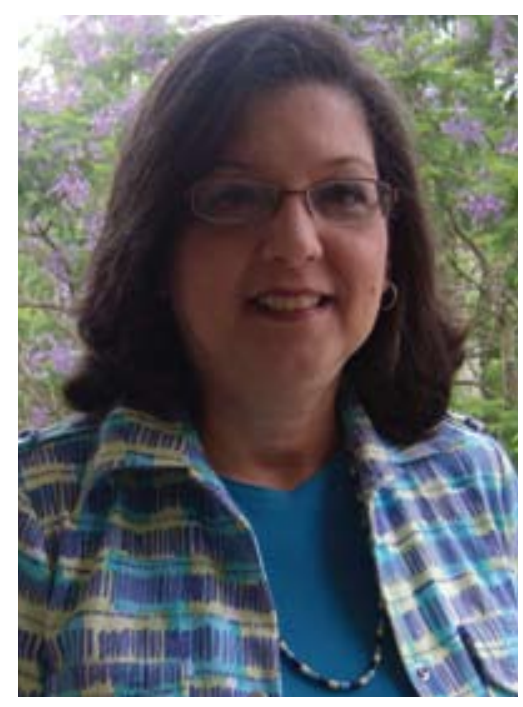

El coloquio, realizado en

México durante el mes de octubre de 2008, tenía como propósito intercambiar ideas y experiencias sobre la evaluación docente universitaria en Iberoamérica y Estados Unidos. Se trataron las diferentes modalidades actuales, los aspectos claves a considerar en estos programas y las características que conforman un modelo comtemporáneo de evaluación.

\title{
NOTAS BIBLOGRÁFICAS
}

\section{RESUMEN DE LAS MEMORIAS DELIV COLOQUIO IBEROAMERICANO SOBRE LA EVALUACIÓN DE LA DOCENCIA 1}

\author{
Idelise Sagredo*
}

El tema de la evaluación docente ha despertado un gran interés en las últimas décadas y se ha conceptualizado usualmente desde una configuración técnica, reduciendo su proceso a la aplicación de instrumentos de medición con fines de control, hasta la calificación, certificación o administración. Sin embargo, la evaluación puede tratarse también como un proceso subjetivo, contextualizado, formativo y participativo en el que inciden diversos factores que contribuyen a mejorar los procesos de formación de los futuros profesionales de la universidad.

En este sentido, las Notas Bibliográficas que sepresentanacontinuaciónsonun resumen de las Memorias del IV Coloquio Iberoamericano sobre la Evaluación de la Docencia, el cual se llevó a cabo en octubre de 2008, en México, D.F. El coloquio formó parte de las actividades que promueve la Red Iberoamericana de InvestigadoressobreEvaluacióndelaDocencia (RIIED). El mismo tuvo como propósitos el intercambio académico sobre la evaluación del desempeño docente en educación superior en Iberoamérica y Estados Unidos, así como el acceso a la información de los diferentes procesos y modalidades actuales que realizan los países participantes. Además, la discusión sobre los aspectos claves a considerar en un programa de este tipo de evaluación, así como las características esenciales de un modelo de evaluación del desempeño docente en el nivel universitario.
Las reflexiones del coloquiogiraronalrededor de los siguientes aspectos: las características preponderantes de las acciones de evaluación del desempeño docente en las instituciones de educación superior en cada país, sus promotores, modalidades más empleadas y los usos más frecuentes de los resultados; asimismo, se analizó el impacto generado y las características fundamentales que debería tener un modelo de evaluación del desempeño docente en el nivel universitario.

\section{Características}

De las características que predominan entre los siete países participantes (Argentina, Colombia, Chile, España, Estados Unidos, México y Venezuela), se destaca la heterogeneidad de instituciones que conforman los sistemas de educación superior en la mayoría de los países, lo que repercute en el proceso evaluativo.

Se evidencia la presencia de acciones de evaluación del desempeño docente que surgen o se incrementan, en la mayoría de los casos, en la década de los noventa. Esto último, debido a los procesos de reformas educativas, al movimiento de rendición de cuentas y la expansión acelerada de políticas públicas de evaluación. Sin embargo, estas acciones reflejan un avance limitado en la producción de instrumentos confiables que permitan hacer recomendaciones y tomar decisiones, que contribuyan a alcanzar la meta común de mejorar la función docente

'El texto se publicó en la Revista Iberoamericana de Evaluación Educativa 1 (3) y está disponible completo en línea en: http://rinace.net/riee/numeros/vol1-num3_e/RIEE-Vol1Num3_e.pdf

"Magíster en Educación, University of Louisville, Kentucky, Estados Unidos. Estudios de Planificación y Administración de la Educación Superior en el Instituto Tecnológico de Santo Domingo y Evaluación de la Calidad de Centros Educativos en la Pontificia Universidad Católica Madre y Maestra. Orientadora Académica y Vocacional del Departamento de Orientación de esta última universidad, en el Campus de Santiago. 
A pesar de que en la mayoría de las instituciones universitarias de los países participantes la función docente constituye la actividad de más demanda, la misma ha sido subvalorada con respecto a la investigación o la extensión. Por tanto, se nota una ausencia permanente de políticas claramente dirigidas al desarrollo de la docencia universitaria en sí misma.

Los propósitos de la evaluación de la práctica docente generalmente se orientan a programas de compensación salarial. En tal sentido, esto contribuye a fortalecer la apreciación de que las acciones evaluativas de la docencia cumplen funciones de control y fiscalización tanto gubernamental como social, más que la búsqueda de condiciones para el desarrollo profesional de los profesores y la mejora institucional, en miras de que se manifieste en la calidad de la formación de los estudiantes.

En el coloquio se enfatizó la conveniencia de diferenciar las funciones designadas a los académicos universitarios: docencia, investigación, difusión y servicio. Esto, a fin de distinguir su participación en programas especiales de compensación salarial o acreditación con miras a especificar su evaluación de acuerdo al rol desempeñado y contribuir a mejorar sus distintas funciones.

Por último, la perspectiva general traza "la directriz de fortalecer la sistematización de experiencias de evaluación del desempeño docente, lo que puede constituir el primer paso para someter los programas de evaluación, en conjunto y en cada uno de sus componentes, a su mejora permanente" (p. 4)

\section{Promotores}

La evaluación docente dentro de las instituciones es reglamentada, en la mayoría de casos, por instancias superiores de autoridad tales como la Rectoría, Vicerrectoría Académica o unidades de planeamiento o gestión. Se reconoce que, enfavor de la mejora del proceso de enseñar y aprender, los distintos niveles de gobierno, las instituciones, los directivos de los sistemas educativos y los diversos actores sociales tienen que asumir responsabilidades. Por tanto, el proceso se hace complejo y de gran envergadura.

\section{Modalidades}

A pesar de que en algunos de los países se utilizan diversas modalidades de evaluación tales como auto-evaluación, evaluación de pares y del jefe directo, la evaluación de la docencia reposa principalmente en la opinión de los estudiantes a través de encuestas y cuestionarios. Las preguntas en conjunto se orientan al estilo de enseñanza, a la relación estudiante-maestro y a aspectos administrativos.

En este sentido, los diversos expositores coinciden en recomendar la inclusión de diversas estrategias para evaluar a los docentes. Se favorece el empleo de los portafolios docentes para evaluar competencias, que ligan la evaluacióncon programas de formación continua, como una manera de contrarrestar el predominio de los cuestionarios de opinión de los estudiantes.

\section{Usos más frecuentes}

Los resultados de la evaluaciónsonutilizados pararetroalimentar a los profesores mismos, a los directores de los departamentos, a las instancias académico-administrativas (decanos y equipo rectoral). En algunos casos, la evaluación de la práctica docente es utilizada para el acceso a la función docente y la promoción, sin que se perciban acciones que lleven a la mejora del proceso enseñanza - aprendizaje.

\section{Características fundamentales del modelo de evaluación}

Al constituir la docencia uno de los componentes medulares del proceso educativo es favorable la evaluación de su práctica, pero a condición de que el enfoque utilizado sea formativo y de perfeccionamiento permanente. Para esto, el grupo de académicos de la RIIED sugiere que, desde su diseño e implementación, los programas de evaluación del desempeño consideren las siguientes dimensiones:

1. Dimensión Política: Supone reconocer el carácter político, ético y orientado al logro de la misión organizacional tomando en consideración el contexto, las necesidades y las características institucionales. De igual forma, implica explicar los propósitos y las repercusiones, así como involucrar, durante todo el proceso, a los diferentes actores de la comunidad educativa para consolidar la participación, la promoción de la autoestima y alentar la autorreflexión.

2. Dimensión teórica: Se ha de explicar en cuál modelo educativo se basa la evaluación, articulando las funciones de docencia, investigación y extensión asignadas a los académicos de la institución. Se deben incorporar los aportes que realizan las Ciencias Humanas y Sociales en relación a los complejos procesos educativos. Además, se requiere concebirla como

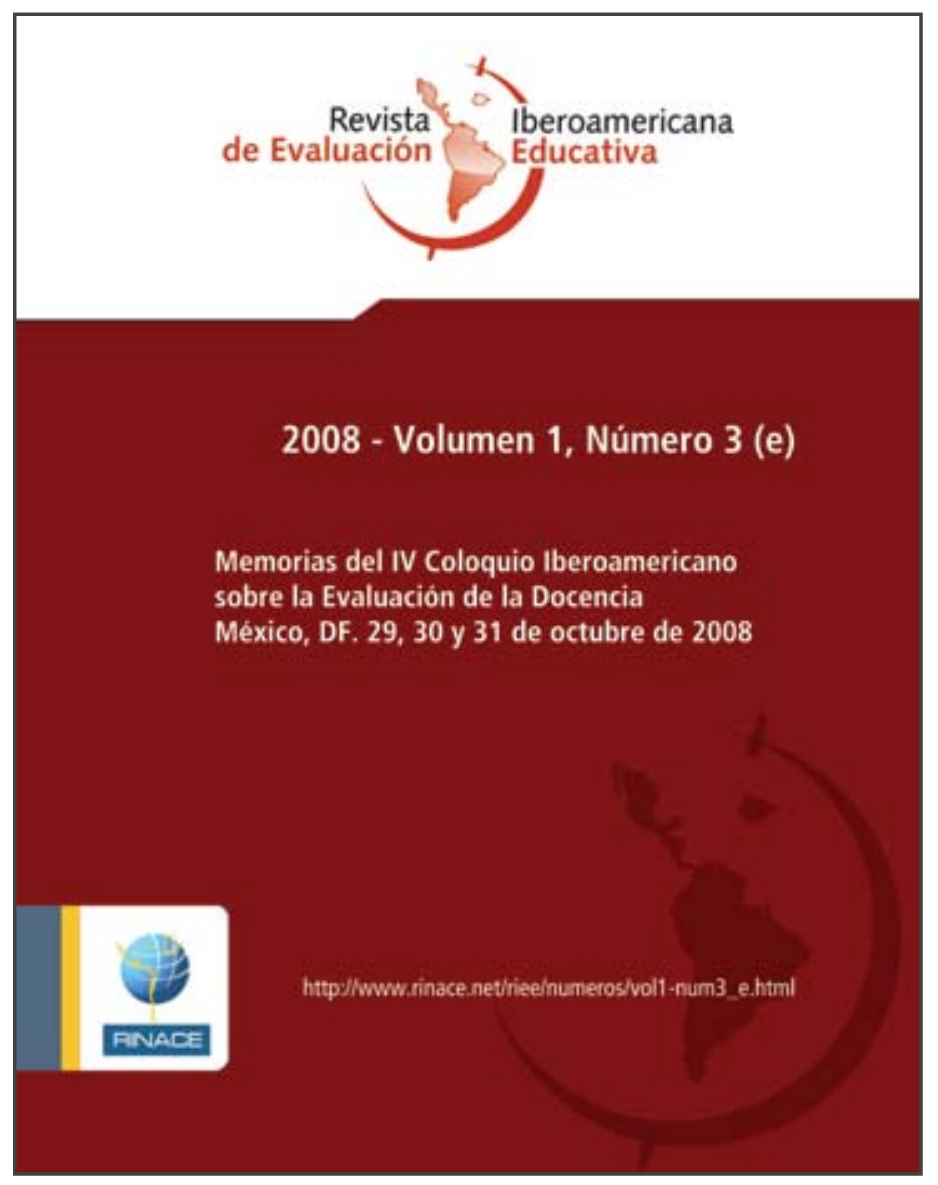


oportunidad para reflexionar y cuestionar las características esenciales en las experiencias de enseñar y aprender.

3. Dimensión Metodológica-Procedimental: Se deben tomar en consideración las experiencias anteriores de evaluación, las características en cuanto a la gestión académica y administrativa, así como el plan de estudios donde se desarrolla la función docente y las condiciones específicas de cada profesor. Para el logro de la credibilidad y confianza, además de hacer públicos los criterios de evaluación, han de utilizarse diferentes fuentes de información y contar con un equipo especializado.

4. Dimensión de Uso: Se requiere delimitar los usos que serán dados a la evaluación y los fines de la misma. Asimismo, implica comunicar a los docentes los resultados para vincular acciones conjuntas que lleven a la mejora de la práctica docente.

5. Dimensión Evaluación de la Evaluación (Meta-evaluación): Conlleva monitorear cada una de las etapas del programa de evaluación. Además, permite dar participación a organismos colegiados internos y externos que valoren y realicen propuestas de mejoras a los procedimientos, indicadores e instrumentos. Igualmente, se necesita desarrollar investigaciones que permitan elaborar nuevas consideraciones teóricas y metodológicas para la evaluación docente.

\section{Experiencias de Evaluación}

Tres experiencias de evaluación formaron parte del Coloquio: la evaluación como práctica reflexiva, el modelo de evaluación de competencias y el portafolio como instrumento de evaluación docente.

Los planteamientos actuales acerca de la evaluación la sitúan como un proceso reflexivo que debe llevarse a la práctica de manera integral, continua y con sentido formativo y participativo. Esto supone una revisión planificada, sistemática y reflexiva de la docencia estableciendo las condiciones apropiadas para que los docentes se involucren y participen en procesos de análisis y reflexión sobre sus propias creencias y prácticas de enseñanza. A partir de una experiencia desarrollada en una universidad chilena, las autoras narran cómo el análisis de distintos sistemas de evaluación docente en varias carreras, desde la perspectiva de profesores y estudiantes, logró acuerdos para el diseño de un nuevo sistema de evaluación. En ella los profesores decidieron qué tipo de cambios mejorarían su trabajo cotidiano como profesionales de la enseñanza.

Otra experiencia presentada es el modelo de evaluación de competencias que desde hace varios años desarrolla la RIED, el cual define el perfil docente como un conjunto de competencias que integran conocimientos, habilidades y actitudes que se ponen en marcha para propiciar ambientes de aprendizaje. Dicho modelo tiene como propósito el orientar las actividades de los docentes y directivos en los procesos de evaluación, resaltando la importancia de la función docente y el cooperar para que la implementación de los procesos de evaluación sea justa y pertinente, de manera que incida en mejores prácticas para la enseñanza. En la elaboración de ese modelo se consideraron los siguientes aspectos: el marco conceptual, la delimitación del propósito central para que los resultados de la evaluación incidan en la creación de programas de actualización docente, el enfoque basado en competencias, el impacto de las políticas públicas fundadas en la evaluación y la urgencia de contribuir a la orientación de una gran cantidad de actores involucrados. El estudio constituye un intento para que la evaluación del desempeño docente sea considerada con responsabilidad por sus actores, en el marco del desarrollo de la autonomía y la autorregulación.

Finalmente, como alternativa para la realización de una evaluación holística del desempeño docente, se propone el portafolio como instrumento de evaluación y reflexión. Se enfatiza que los portafolios son muy ventajosos para identificar la calidad del trabajo docente y las necesidades de actualización de los profesores. Esta situación pone en ventaja este recurso con respecto a la información limitada que ofrecen las encuestas. Los resultados del estudio identificaron áreas de mejora que posteriormente fueron utilizadas para el desarrollo de un programa de formación en la región. La fortaleza de los portafolios depende del tipo y calidad de la información que incluyan, reconociendo la existencia de elementos claves de la calidad de la enseñanza que sólo la observación directa en el aula puede poner al descubierto.

\section{Reflexión sobre este resumen}

La lectura minuciosa de cada uno de los trabajos, tal y como invita Rueda Beltrán a efectuar en el Editorial del documento, conduce a comparar estas experiencias evaluativas con el proceso de evaluación docente de nuestra Institución. En tal sentido, se puedeapreciar quelaPUCMMesunainstituciónquehaidoacorde con los desafíos de los tiempos, pues desde la década de los setenta, los docentes hemos sido evaluados a través de diversas modalidades, predominando el cuestionario de los estudiantes. No obstante, en algún momento se realizaron observaciones en el aula por parte de los Directores, evaluaciones de pares, grupos focales, evaluaciones de los Decanos y de expertos. También las investigaciones, las publicaciones y los trabajos comunitarios, entre otros, han sido aspectos considerados a la hora de evaluar al profesorado.

De igual forma, hemos llevado a cabo debates acerca de lo que significa ser un buen profesor, sus características y funciones. No han faltado las inquietudes sobre cuáles aspectos tomarse en consideración para la formación de los docentes: si debe basarse en el área profesional o en los procesos pedagógicos específicos de cada carrera. Por otra parte, en el proceso de evaluación docente se han realizado análisis sobre el modelo educativo que sustenta nuestra acción.

Cabe aquí recordar lo señalado por Robert Stake de que la evaluación docente es un tema mucho más complejo que los procedimientos e instrumentos formales e informales con los que actualmente contamos para determinar su calidad. Hay múltiples realidades e informantes. Decisiones importantes para universidades o profesores no deben basarse en un solo indicador o anécdota. "Por ética estamos obligados a usar múltiples fuentes de información para tomar decisiones sobre su futuro." (p. 26) 